\title{
Improvement of journal bearing operation at heavy misalignment using bearing flexibility and compliant liners
}

Thomsen, Kim; Klit, Peder

Published in:

Proceedings of the Institution of Mechanical Engineers, Part J: Journal of Engineering Tribology

Link to article, DOI:

$10.1177 / 1350650112439372$

Publication date:

2012

Document Version

Publisher's PDF, also known as Version of record

Link back to DTU Orbit

Citation (APA):

Thomsen, K., \& Klit, P. (2012). Improvement of journal bearing operation at heavy misalignment using bearing flexibility and compliant liners. Proceedings of the Institution of Mechanical Engineers, Part J: Journal of Engineering Tribology, 226(8), 651-660. https://doi.org/10.1177/1350650112439372

\section{General rights}

Copyright and moral rights for the publications made accessible in the public portal are retained by the authors and/or other copyright owners and it is a condition of accessing publications that users recognise and abide by the legal requirements associated with these rights.

- Users may download and print one copy of any publication from the public portal for the purpose of private study or research.

- You may not further distribute the material or use it for any profit-making activity or commercial gain

- You may freely distribute the URL identifying the publication in the public portal 


\title{
Improvement of journal bearing operation at heavy misalignment using bearing flexibility and compliant liners
}

\author{
Proc IMechE Part J: \\ J Engineering Tribology \\ 226(8) 65I-660 \\ (C) IMechE 2012 \\ Reprints and permissions: \\ sagepub.co.uk/journalsPermissions.nav \\ DOI: I0.I I77//350650 I I 2439372 \\ pij.sagepub.com
}

(SAGE

\author{
Kim Thomsen and Peder Klit
}

\begin{abstract}
A flexure journal bearing design is proposed that will improve operational behaviour of a journal bearing at pronounced misalignment. Using a thermoelastohydrodynamic model, it is shown that the proposed flexure journal bearing has vastly increased the hydrodynamic performance compared to the stiff bearing when misaligned. The hydrodynamic performance is evaluated on lubricant film thickness, pressure and temperature. Furthermore, the influence of a compliant bearing liner is investigated and it is found that it increases the hydrodynamic performance when applied to a stiff bearing, whereas the liner has practically no influence on the flexure journal bearing's performance.
\end{abstract}

\section{Keywords}

Flexure bearing, thermoelastohydrodynamic, misalignment, polymer liner

Date received: 24 October 20I I; accepted: 27 January 2012

\section{Introduction}

Misalignment is the root cause of many journal bearing failures. It is, however, difficult to avoid misalignment since many factors add to it. These are improper assembly, elastic and thermal distortions of the shaft and bearing housing, and also manufacturing tolerances. Therefore, it is important to consider misalignment when designing journal bearings. A traditional solution for misalignment is to include a spherical seat in the housing and thereby allow the bearing to rotate and align to the journal at the assembly. This will, however, only apply a static correction and not permit any dynamic misalignment. Another design approach is to add a well-defined crowning for the bearing liner. This approach can be problematic since the required liner modification is smaller than 0.5 times the minimum lubricant film thickness and therefore difficult to manufacture.

The aim of this study is to show that bearing flexibility can be used to effectively improve a bearing's ability to operate under heavy misalignment. It is accomplished by decreasing the angular stiffness of the bearing and at the same time maintaining a high radial stiffness. This allows the bearing to maintain a high performance at low or no misalignment and also to deform when subjected to misalignment. Thereby, the lubricant film thickness is increased at the highly loaded areas that could otherwise make contact and lead to failure.

In this study, the term flexure bearing is used for bearings for which important parts of their tribological characteristics are achieved through structural flexibility.

In this study, it is shown that by using a flexure bearing design, it is possible to design an inexpensive, simple and robust bearing that can operate at high misalignment without suffering from edge loading and potential bearing damage. Furthermore, it is also studied if a compliant liner will improve the tolerance towards misalignment when combined with a flexure bearing and also on a traditional stiff bearing.

Department of Mechanical Engineering, Technical University of Denmark, Denmark

\section{Corresponding author:}

Kim Thomsen, Department of Mechanical Engineering, Technical University of Denmark, Nils Koppels Alle, Building 404, DK-2800 Kgs, Lyngby, Denmark.

Email: kimth@mek.dtu.dk 
Bouyer, Fillon and Pierre have done an extensive work $^{1-4}$ on the effects of misalignment on the operational behaviour of traditional journal bearings. They observe the most significant reduction in bearing performance at low rotational speed and as expected, the pressure peak moves away from the centre plane and towards the edge of the bearing when subjected to misalignment. They propose two optimized bearing geometries and show that they can improve performance considerably when operating with misalignment. However, they do not take elasticity into account.

Nikolakopoulos et al. ${ }^{5}$ show a novel application of bearing optimization using Pareto analysis together with an elastohydrodynamic (EHD) model. They optimize the geometry of a misaligned journal bearing through variation of the traditional bearing parameters. It is also shown that a misaligned bearing can benefit from a limited amount of wear.

Mihailidis et al. ${ }^{6}$ study the influence of bushing geometry on the performance of a misaligned hydrodynamic journal bearing and find that parabolic and crowned liner modifications perform well.

A flexure bearing is designed to take advantage of its structural flexibility in order to adapt its geometry to various operating conditions. The bearings are known as alternatives to pivoted bearings, for both radial and thrust bearings.

Walton and San Andrés ${ }^{7}$ study a four-pad flexure bearing subjected to various operating conditions experimentally and compare measurements with theoretical results. They find that the particular bearing geometry operates predictably and reliably for all subjected conditions. San Andrés and de Santiago ${ }^{8}$ study the dynamic response of a flexure pad bearing experimentally. They find that bearing response to unbalance loads is good and has a stable performance in the entire range of operating conditions.

Thomsen and $\mathrm{Klit}^{9}$ study a radial flexure pad bearing operating under misaligned conditions and it is found that the use of flexure pads is an attractive alternative to pivoted pads. Pivot contact related failure modes are eliminated and load capacity is not restricted by the force that can be transferred through the pivot contact. It is furthermore found that if the flexure support is combined with a polymer liner, it is possible to design a very robust pad that can operate at higher specific loads than common babbitted tilting pad bearings.

The study of compliant liners has seen increasing interest in the recent years. Due to the polymer liners' low break away friction and good wear properties, the liners have very good operational characteristics at thin films. The compliant nature of the polymer bearings mean that they are less sensible to imperfections in the bearing surface geometry. This is particularly interesting for large bearings. The polymers do, however, also give the design engineers new challenges in the form of creep, the Achilles' heel of polymers when applied to bearing applications. In order to decrease the creep to an acceptable level, the polymers are often reinforced with glass or carbon fibres. The low thermal conductivity of polymers must also be taken into account when introducing polymer liners in hydrodynamic bearings, as it will reduce the heat flux between bearing and lubricant.

Simmons et al. ${ }^{10}$ analyse the use of large thrust pads with polytetrafluoroethylene (PTFE) liners for hydropower plants and describe the learning from uprating the thrust bearing in a hydropower plant. The existing babbitt-faced pads were replaced with PTFE-faced pads and it was concluded that the high-pressure lubricant-injection systems used to enable safe start-up and shut-down could be dispensed with. The PTFE pads can operate under harder conditions, allowing the bearings to be designed smaller and thus more energy efficient or with similar size as a babbitted bearing but with a higher safety margin.

Thomsen and Klit ${ }^{11}$ study the compliant liners and their influence on the dynamic response of a dynamically loaded journal bearing. The primary findings are that the maximum pressures are reduced significantly at the expense of slightly higher eccentricity ratio during operation.

As stated earlier, the aim of this study is to show that bearing flexibility can be used for bearings operating at heavy misalignment advantageously. A traditional twolobe journal bearing with circular bore operating at steady-state conditions is used for the analysis. A stiff bearing and a flexure bearing geometry will be studied and compared. In addition to this, the effects of compliant liners are studied by including variants with and without compliant bearing lining. Thus, four bearings are studied in total:

- a traditional stiff bearing;

- a traditional stiff bearing with compliant polymer liner;

- a flexure bearing; and

- a flexure bearing with compliant polymer liner.

Figure 1 shows the geometry of the flexure journal bearing with a compliant liner. The low rotational stiffness of the flexure web allows the flexure tube, and thus the bearing, to rotate and adjust according to journal misalignment.

The compliant liner is $2-\mathrm{mm}$ thick. For the bearings without a compliant liner, the steel bodies are moved $2 \mathrm{~mm}$ towards the bearing centre line and thereby the overall stiffness of the bearings is influenced minimally when removing the compliant liners. The two stiff 
bearings are modelled using the same figure, except that the web of $15 \mathrm{~mm}$ is extended to the full width of $150 \mathrm{~mm}$. The journal is assumed infinitely stiff. Remaining bearing data and operating conditions are given in Table 1. The same operating conditions are used throughout the analysis.

The full flexibility of the bearing is included in the elastic model, and thus, there is an exhaustive number of geometrical parameters to investigate when optimize

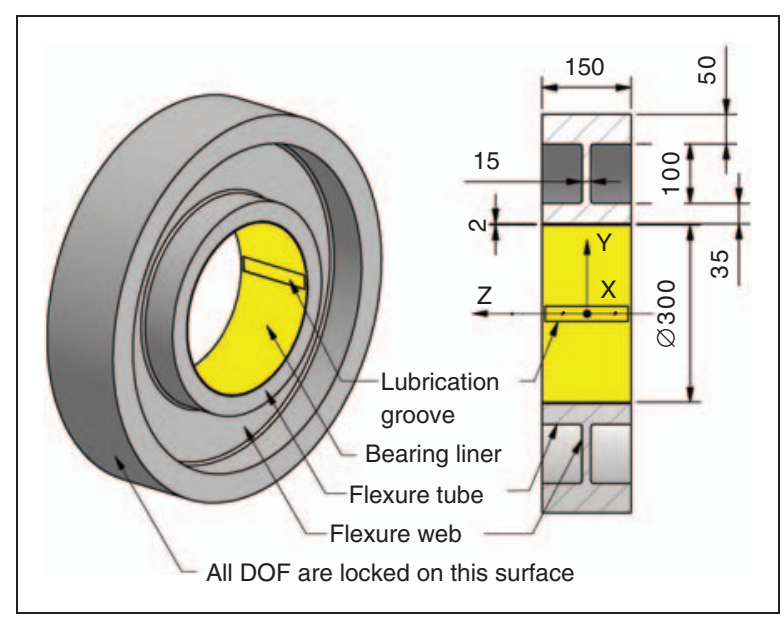

Figure I. Flexure journal bearing geometry and system coordinates.

DOFs: degrees of freedom.

Table I. Bearing data and operating conditions.

\begin{tabular}{ll}
\hline Parameter & Value \\
\hline Bearing diameter & $300 \mathrm{~mm}$ \\
Bearing width, $L$ & $150 \mathrm{~mm}$ \\
Radial clearance & $150 \mu \mathrm{m}$ \\
Circumferential extension of oil inlet groove & $10^{\circ}$ \\
Number of oil inlets & 2 \\
Bearing load in y-direction & $-225 \mathrm{kN}$ \\
Specific pressure & $5 \mathrm{MPa}$ \\
Rotational speed, $\omega$ & $1500 \mathrm{r} / \mathrm{min}$ \\
Lubricant viscosity grade & $150 \mathrm{VG} 32$ \\
Lubricant density, $\rho$ & $854 \mathrm{~kg} / \mathrm{m}^{3}$ \\
Lubricant specific heat capacity, $c_{p}$ & $2000 \mathrm{~J} / \mathrm{kg} / \mathrm{K}$ \\
Oil inlet temperature & $40{ }^{\circ} \mathrm{C}$ \\
Journal temperature at bearing edges & $40{ }^{\circ} \mathrm{C}$ \\
Polymer liner: modulus of elasticity & $6 \mathrm{GPa}$ \\
Polymer liner: Poisson's ratio & 0.4 \\
Steel: modulus of elasticity & $200 \mathrm{GPa}$ \\
Steel: Poisson's ratio & 0.3 \\
Journal thermal conductivity, $k_{j}$ & $40 \mathrm{~W} / \mathrm{m} / \mathrm{K}$ \\
Heat transfer coefficient: journal/oil $\alpha_{j}$ & $2000 \mathrm{~W} / \mathrm{m}^{2} / \mathrm{K}$ \\
\hline
\end{tabular}

the geometry for the given load. For this study, the thickness of the flexure web and flexure tube, $15 \mathrm{~mm}$ and $35 \mathrm{~mm}$, respectively, was chosen after trying several configurations. This particular combination returns good bearing response, although not fully optimized, for the given operating conditions.

\section{Governing equations and model set-up}

A thermoelastohydrodynamic model has been developed for this study on flexure bearings. A brief description of the simulation model and its sub-models is given in the following sections.

The hydrodynamic part of the model is verified using the bearing geometry and loads from the connecting rod big end bearing of the Hornsby 6VEB-X Mk III 4 stroke diesel engine ${ }^{12}$ giving identical results as other studies. The elasticity part is verified by comparison with elastic structures where the deformation can be compared with elementary beam theory. The thermal part is difficult to compare directly with other studies since, in this article, one surface is treated as adiabatic and heat transfer through the other surface is calculated using a heat transfer coefficient. Furthermore, the journal temperature varies axially in this study. The approach has, however, been widely used and accepted as a simplified method for thermoelastohydrodynamic modelling.

\section{Reynolds equation}

A three-node triangular fine element method (FEM) model is used for solving the steady-state form of Reynolds equation (1) and thus finding the pressure distribution

$$
\frac{1}{R} \frac{\partial}{\partial \theta}\left[\frac{h^{3}}{\mu R} \frac{\partial p}{\partial \theta}\right]+\frac{\partial}{\partial z}\left[\frac{h^{3}}{\mu} \frac{\partial p}{\partial z}\right]=6 \omega \frac{\partial h}{\partial \theta}
$$

The element equations corresponding to equation (1) are derived using the variational approach ${ }^{13}$ and shown in equations (2) to (4). Three-node triangular elements are used, giving linear interpolation functions. The coefficients $b$ and $c$ are constants of the element and are deduced from its geometry

$$
\underset{3 \times 3}{\left[\mathbf{H}_{j k}\right]} \underset{3 \times 1}{\left\{p_{j}\right\}}=\underset{3 \times 1}{\left\{V_{j}\right\}}
$$

$$
\left[\mathbf{H}_{j k}\right]=\int_{\Omega}\left(\frac{h^{3}}{4 \mu A^{2}}\left(b_{j} b_{k}+c_{j} c_{k}\right)\right) \mathrm{d} \Omega
$$

$$
\left\{V_{j}\right\}=\int_{\Omega}\left(\frac{3 R b_{j}}{A} \omega h\right) \mathrm{d} \Omega
$$


Equation (2) is a set-up for all elements and assembled into a set of equations, combining all nodes which can then be used to solve for the pressure $p$.

The pressure is set to zero for all nodes located on the bearing edges and in the lubrication grooves.

Cavitation is handled through an algorithm where consecutive iterations are solved for the pressure. Nodes which fulfil the cavitation requirement, $p<0$, are identified and a fraction of the nodes, counting from the trailing edge of the cavitated region, is selected and the pressure is set to zero at these nodes and next iteration is initiated. The procedure is repeated until no nodes fulfil the cavitation requirement.

\section{Elasticity}

An industrial state-of-the-art structural finite element program, in this case Ansys, ${ }^{14}$ is used to create the bearing models in order obtain the corresponding stiffness matrices. Since the fluid film forces are acting only on the liner surface, it is advantageous to condense the stiffness matrices into super elements before exporting them. The method of exporting and reading the stiffness matrix $\mathbf{K}$ is verified by modelling geometries that can be compared to analytical results using elementary beam theory. The force stiffness matrix $\mathbf{K}$ is converted to pressure compliance matrix $\mathbf{L}$ using the integration matrix $\mathbf{A}$, as shown in equation (5)

$$
\begin{aligned}
{[\mathbf{K}]\{d\} } & =\{F\} \Leftrightarrow\{d\}=[\mathbf{K}]^{-1}\{F\}=[\mathbf{K}]^{-1}[\mathbf{A}]\{p\} \\
& =[\mathbf{L}]\{p\}
\end{aligned}
$$

The super elements utilize 5500 elements. The meshes from the super elements are also used for the oil film model using equations (2) to (4). For the structural model, all nodes at the outer surface of the bearing in Figure 1 are locked in all its degrees of freedom.

\section{Coupling of oil film forces and elasticity}

Reynolds equation is coupled with bearing elasticity using the Newton-Raphson method. A Taylor expansion around the solution $f(p)$ with respect to $p$ and neglecting derivatives of orders higher than one gives equation (6)

$$
\Delta p \frac{\partial f(p)}{\partial p}=f(p+\Delta p)-f(p)
$$

The functionals $f(p)$ (7) and $f(p+\Delta p)$ (8) are the usual Reynolds equation (1) where the latter is perturbed with respect to the pressure. The two functionals are expanded and simplified to equation (9) using (6).
The term $h_{0}$ is the oil film thickness for the flexure bearing in its undeformed state

$$
f(p)=\frac{1}{R} \frac{\partial}{\partial \theta}\left(\frac{h^{3}}{\mu R} \frac{\partial p}{\partial \theta}\right)+\frac{\partial}{\partial z}\left(\frac{h^{3}}{\mu} \frac{\partial p}{\partial z}\right)-6 \omega \frac{\partial h}{\partial \theta}
$$

where $h=h_{0}+L p$

$$
\begin{aligned}
f(p+\Delta p)= & \frac{1}{R} \frac{\partial}{\partial \theta}\left(\frac{h^{3}}{\mu R} \frac{\partial(p+\Delta p)}{\partial \theta}\right) \\
& +\frac{\partial}{\partial z}\left(\frac{h^{3}}{\mu} \frac{\partial(p+\Delta p)}{\partial z}\right)-6 \omega \frac{\partial h}{\partial \theta}
\end{aligned}
$$

where $h=h_{0}+L(p+\Delta p)$

When $h^{3}$ from equation (8) is expanded, the terms including $L \Delta p$ in powers of two or higher are neglected

$$
\begin{aligned}
\Delta p \frac{\partial f(p)}{\partial p}= & \frac{1}{R} \frac{\partial}{\partial \theta}\left(\frac{3 h^{2} L \Delta p}{\mu R} \frac{\partial p}{\partial \theta}\right)+\frac{\partial}{\partial z}\left(\frac{3 h^{2} L \Delta p}{\mu} \frac{\partial p}{\partial z}\right) \\
& +\frac{1}{R} \frac{\partial}{\partial \theta}\left(\frac{h^{3}}{\mu R} \frac{\partial \Delta p}{\partial \theta}\right)+\frac{\partial}{\partial z}\left(\frac{h^{3}}{\mu} \frac{\partial \Delta p}{\partial z}\right) \\
& -6 \omega \frac{\partial L \Delta p}{\partial \theta}
\end{aligned}
$$

where $h=h_{0}+L p$

Equation (9) is then put into finite element formulation, using the Galerkin principle, giving the left-hand side (LHS) of equation (10), which is then used to solve for $\Delta p$ where $S$ is the residual of the assembled version of equation (2) after the right-hand side (RHS) is moved to the LHS

$$
\left[\frac{\partial f(p)}{\partial p}\right]\{\Delta p\}=\{S\}=[\mathbf{H}]\{p\}-\{V\}
$$

The final solution for the state of deformation $d$ and the corresponding pressure $p$ is found by solving equation (10) multiple times until the residual $S$ vanishes.

For a thorough derivation of the Newton-Raphson method applied for EHD problems, see McIvor's ${ }^{15}$ work on this topic.

\section{Energy equation}

The energy equation (11) is solved using a two-dimensional model. The local temperature $T_{m}$ represents the mean temperature over the film thickness direction. The lubricant temperature is specified at the lubricant supply grooves and full lubricant exchange is assumed

$$
\begin{aligned}
\rho c_{p} & \left(\frac{1}{R} \frac{\partial T_{m}}{\partial \theta} q_{\theta}^{\prime}+\frac{\partial T_{m}}{\partial z} q_{z}^{\prime}\right) \\
= & \alpha_{J}\left(T_{J}-T_{m}\right)+\frac{\mu_{m} \omega^{2} R^{2}}{h} \\
& +\frac{h^{3}}{12 \mu_{m}}\left(\frac{1}{R^{2}}\left(\frac{\partial p}{\partial \theta}\right)^{2}+\left(\frac{\partial p}{\partial z}\right)^{2}\right)
\end{aligned}
$$


The conductive term only includes conduction through the journal; this is a good boundary condition when the bearing is covered with a highly thermally insulating polymer liner. It does, however, give an underestimation of the heat conduction from the lubricant when the model is used for the metal lined bearings, because the heat transport through the liner is neglected. The approach is chosen in order to be able to compare the four bearing configurations without complicating the evaluation of the results.

The conduction is calculated using the heat transfer coefficient $\alpha_{J}$ together with the temperature difference between journal and lubricant: $T_{J}-T_{m}$.

The journal temperature profile in the axial direction $T_{J}(z)$ is determined assuming that the journal temperature is constant at any radial cross-section $\left(z=z_{c s}\right)$. Thereby, the power conduction through a section of the journal can be calculated using equation (12). The journal temperature is then defined at the bearing edges only $\left(z= \pm \frac{L}{2}\right)$

$$
P_{J_{z=z_{c s}}}=A_{J} k_{J} \frac{\partial T_{J}}{\partial z}
$$

For simplicity, the conduction from lubricant to journal is assumed to be symmetric about the midsection of the bearing $(z=0)$. When this assumption is combined with the conductive term of equation (11), the power through any cross section can also be expressed as equation (13)

$$
P_{J_{z= \pm z c s}}=R \int_{-z_{c s}}^{+z_{c s}} \int_{-\pi}^{+\pi} \frac{\alpha_{J}\left(T_{J}-T_{m}\right)}{2} \mathrm{~d} \theta \mathrm{d} z
$$

Equations (12) and (13) can then be combined into equation (14), expressing the journal temperature gradient at any cross-section of the journal

$$
\frac{\partial T_{J}}{\partial z_{z= \pm z_{c s}}}=\frac{R \int_{-z_{c s}}^{+z_{c s}} \int_{-\pi}^{+\pi} \alpha_{J}\left(T_{J}-T_{m}\right) \mathrm{d} \theta \mathrm{d} z}{2 A_{J} k_{J}}
$$

The axial temperature profile of the journal $T_{J}(z)$ can then be found by solving the boundary value problem described by the differential equation (14) knowing the temperature at $z= \pm \frac{L}{2}$.

The energy equation is solved using the finite difference method. For this purpose, the results from the arbitrary mesh layout of the FEM is interpolated onto the equidistant finite different mesh.

Finally, the Walther and $\mathrm{McCoull}^{16}$ expression is used to describe the temperature and viscosity correlation.

\section{Results}

\section{Variation of misalignment}

A load of $-225 \mathrm{kN}$, corresponding to a specific pressure of $5 \mathrm{MPa}$, is applied to the bearings in the $Y$-direction (see Figure 1 for coordinate system), while increasing the angular misalignment from 0 to $1 \mathrm{mrad}$ around the $X$-axis. This corresponds to a difference of $150 \mu \mathrm{m}$ film thickness from one bearing side to the other, the same as the radial clearance. Nikolakopoulos et al. ${ }^{5}$ states that a misalignment of up to $0.3 \mathrm{mrad}$ is generally accepted in most industrial and marine applications. Figure 2 shows the flexure bearing geometry operating at maximum misalignment in its deformed state. It is seen how the flexible web allows the flexure tube to rotate and adapt to the journal misalignment and thereby increase the film thickness at the hardest loaded area of the bearing. The tube also deforms and bends just over the bearing centre, where the tube is supported by the web. The bending of the tube is undesirable as it creates a pressure peak if the bending is too high. In this case, the tube wall thickness of $35 \mathrm{~mm}$ ensures that the amount of bending

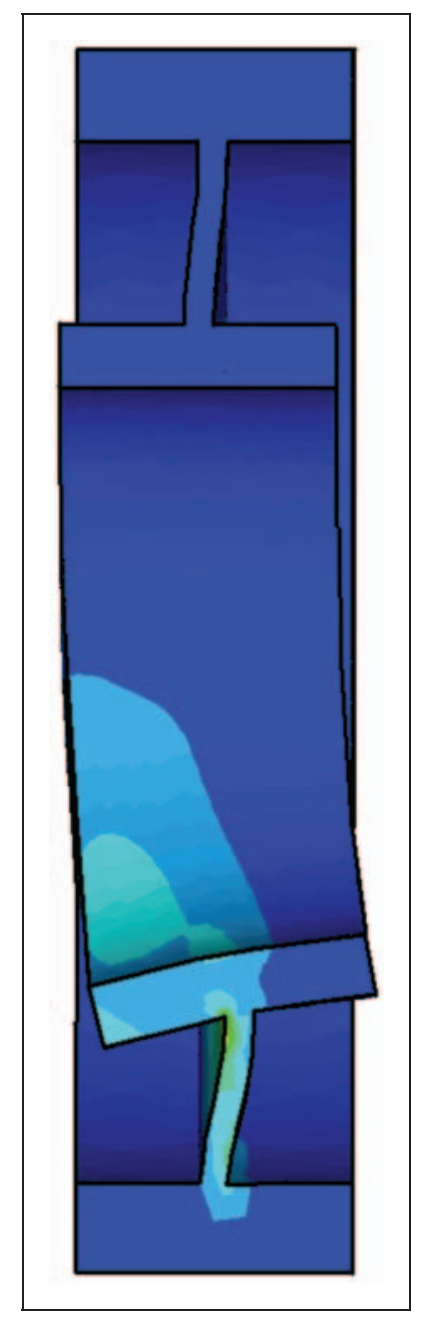

Figure 2. Ansys model showing deformed state of flexure bearing at maximum misalignment. The colour grades represent von Mises reference stress; maximum is $128 \mathrm{MPa}$. 
is limited. The colour grades represent the von Mises stress levels in the bearing, and a maximum stress of $128 \mathrm{MPa}$ is observed. The maximum stress is found at the interface web-to-tube, where no fillets are used in the structural model. Thus, the stress levels can be expected to decrease when introducing these.

Figure 3 shows the minimum film thickness for the four bearing configurations at increasing misalignment. It is seen that the two stiff bearings reach a minimum film thickness of 0.3 and $1.4 \mu \mathrm{m}$ already at $0.44 \mathrm{mrad}$, whereas the two flexure bearings maintain a thickness of $14 \mu \mathrm{m}$ at this amount of misalignment. The flexure configurations maintain a film thickness of more than $3 \mu \mathrm{m}$ up to the maximum misalignment of $1 \mathrm{mrad}$. The gradients of the two flexure bearing curves change from almost horizontal to decreasing at $0.09 \mathrm{mrad}$ misalignment. At this point, the location of the minimum film thickness changes from the midsection of the bearing to the edge.

For the stiff bearing, it is seen that the compliant liner increases the minimum film thickness over the entire range of misalignment with a relative high quantity. The reason for this improvement is that the cavitated area is reduced when using the compliant liner and thus the load-carrying area of the bearing is increased. In the case of the flexure bearing, there is no significant difference when using a compliant liner.

A topic not covered by this study is the wear and friction properties of the compliant polymer liner during mixed lubrication, which is generally better for polymers. McCarthy and Glavatskih ${ }^{17}$ has shown this by comparing polyether ether ketone and babbitt experimentally. Therefore, the bearings with a compliant liner can be operated safely at lower film thicknesses compared to bearings using babbitt liners.

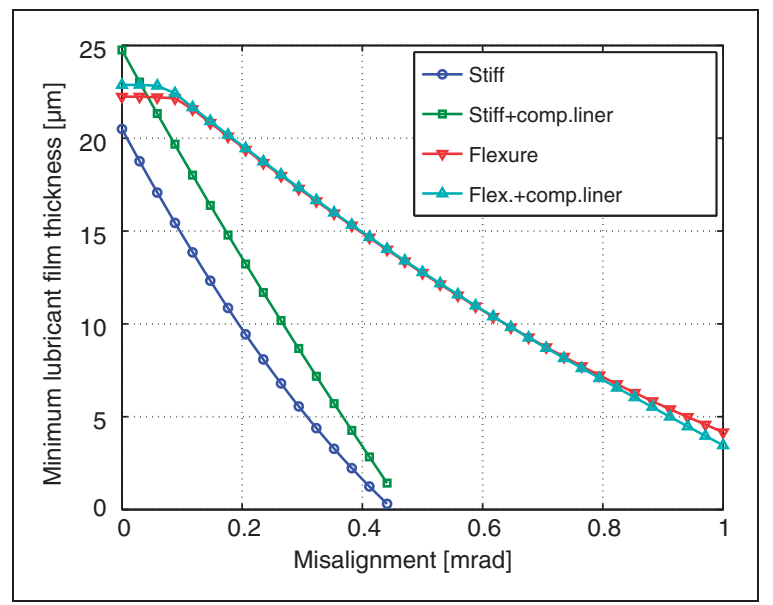

Figure 3. Minimum lubricant film thickness as a function of journal misalignment.
Figure 4 shows the maximum lubricant pressure for the four bearing configurations at increasing misalignment. As expected, the two stiff configurations show rapidly increasing pressures, whereas the two flexure bearings display a very light increase in maximum pressure over the entire range of misalignment. Again, the compliant liner gives remarkably increased performance for the stiff bearing, whereas the performance change is only moderate for the flexure bearing.

Figure 5 shows the maximum lubricant temperature at increasing misalignment. Again, the two stiff configurations display a fast increase to very high values and it is seen that the compliant liner increases bearing performance for the stiff bearing. The flexure bearings display a slowly increasing maximum temperature with misalignment, and there is virtually no difference between the bearings with noncompliant and compliant liner. The model predicts a peak temperature for the stiff bearing of $500{ }^{\circ} \mathrm{C}$ and a minimum film thickness of $0.3 \mu \mathrm{m}$. The simulation model cannot predict reliable results in these ranges since new physical phenomena will show in the form of gas release and asperity contact.

Figure 6 shows the journal eccentricity as a function of misalignment and it is obvious that even though the flexure web is designed to maintain a high radial stiffness, the bearing still suffers from lower stiffness coefficients. It is, however, very counterintuitive that the stiff bearing has a lower stiffness than the corresponding bearing with compliant liner. From this, and also Figure 3, it is evident that the compliant liner improves the hydrodynamic effects and thereby increases the film thickness and correspondingly also increases the bearing stiffness coefficients. The opposite is true for the

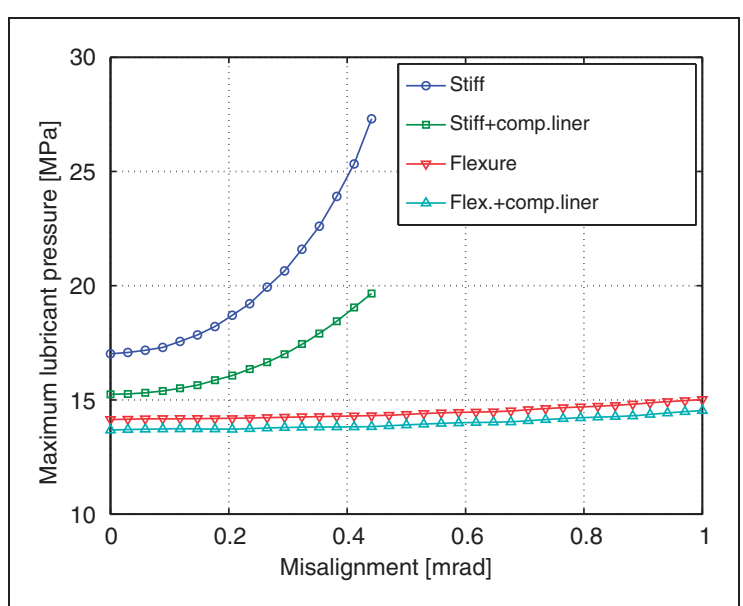

Figure 4. Maximum lubricant pressure as a function of journal misalignment. 


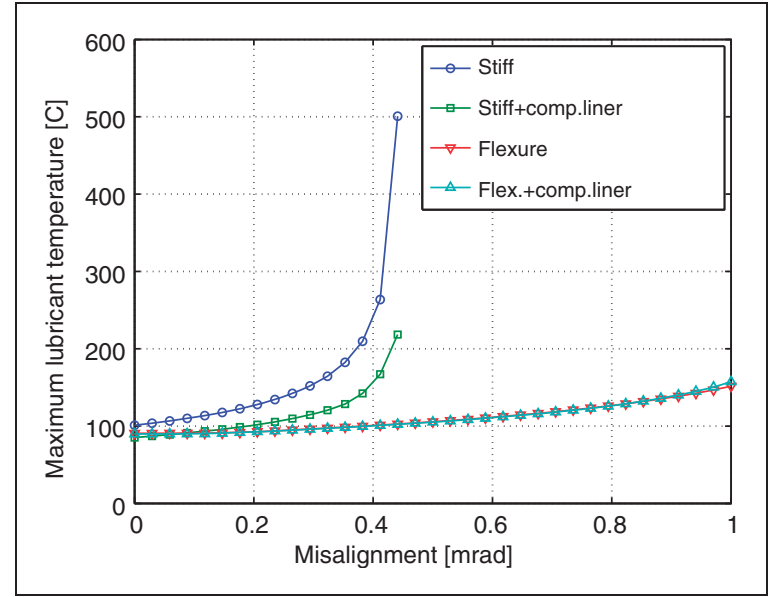

Figure 5. Maximum lubricant temperature as a function of journal misalignment.

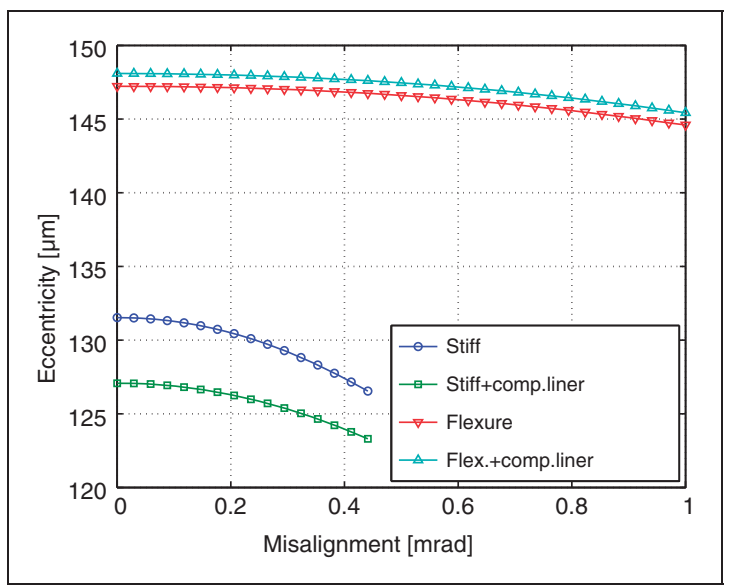

Figure 6. Journal eccentricity as a function of journal misalignment.

flexure bearing where the eccentricity increases slightly with the compliant liner.

\section{Full bearing liner plots}

Figures 7 to 13 show bearing data for the applied load and misalignment corresponding to the point on Figures 3 to 6 that can be read at $0.44 \mathrm{mrad}$, i.e. the last points for the stiff bearings.

Figure 7 shows the pressure profile for the flexure bearing. It is seen that the pressure peak is still very close to the bearing centre and that the profile is comparable to the usual profile from a bearing operating at no misalignment. The mesh is not shown at the cavitated areas.

Figure 8 shows the deformation corresponding to the pressure shown in Figure 7. As expected, the

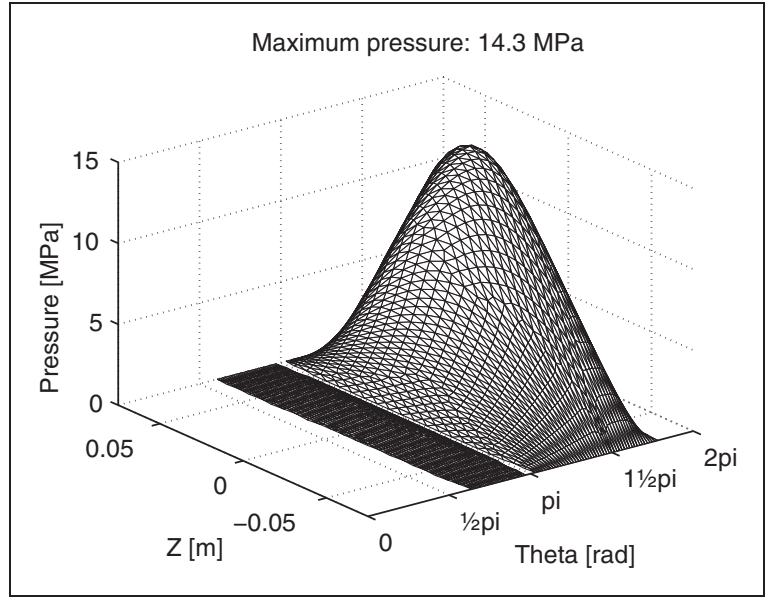

Figure 7. Pressure profile for flexure bearing with $225 \mathrm{kN}$ load and $0.44 \mathrm{mrad}$ misalignment.

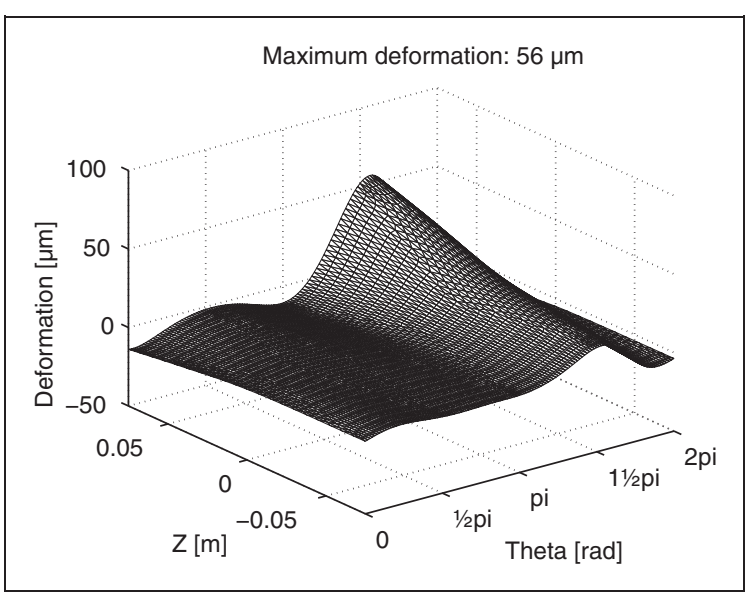

Figure 8. Liner deformation of flexure bearing with $225 \mathrm{kN}$ load and $0.44 \mathrm{mrad}$ misalignment.

bearing has a very high deformation at the area at which the journal tries to make contact due to the misalignment. It is also interesting to see that the deformation is negative in some areas. From this, it can be concluded that the bearing ovalizes under the misaligned bearing load.

Figure 9 shows the lubricant temperature over the flexure bearing liner surface. As expected, the maximum temperature is at the bearing edge, at the same location as the minimum film thickness.

\section{Axial liner plots}

Figure 10 shows the axial pressure profiles for the four bearing configurations. The stiff bearing has very high pressure levels and gradients at the bearing edge, same 


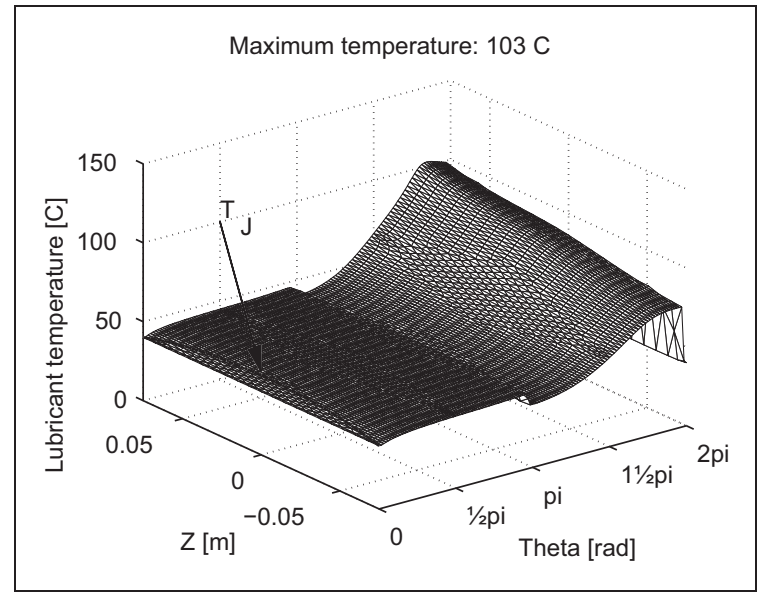

Figure 9. Lubricant mean temperature $T_{m}$ for flexure bearing with $225 \mathrm{kN}$ load and $0.44 \mathrm{mrad}$ misalignment. Axial journal temperature $T_{J}$ profile is also shown. $T_{J_{\max }}=50.3^{\circ} \mathrm{C}$.

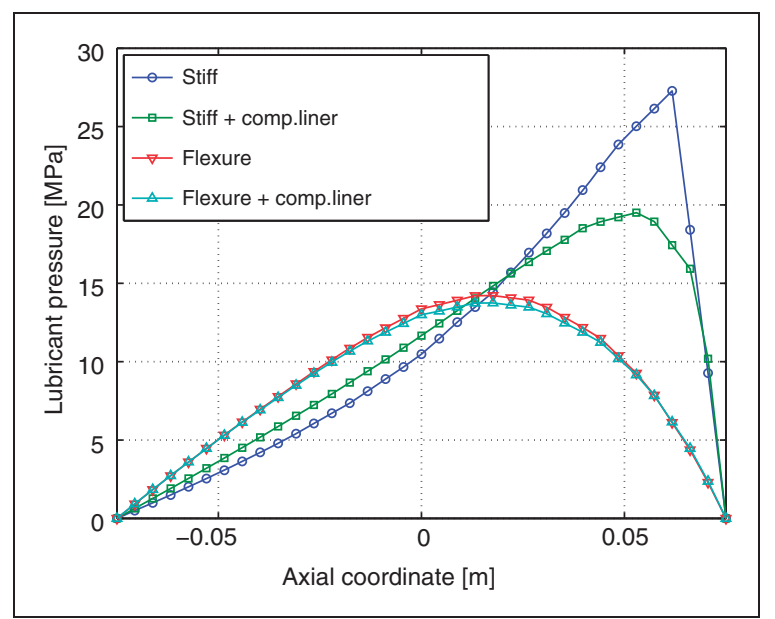

Figure 10. Axial pressure profiles for bearings with $225 \mathrm{kN}$ load and $0.44 \mathrm{mrad}$ misalignment at circumferential location with maximum pressure.

tendency as shown in numerous studies. The compliant liner decreases the pressure level significantly for the stiff bearing, but there is no significant change for the flexure bearing. It is seen that the pressure profiles for the flexure bearings are close to the typical pressure profile of a nonmisaligned bearing.

Figure 11 shows the axial film thickness profiles. The stiff bearing shows an almost linear film thickness variation, whereas the stiff bearing with a compliant liner has a higher gradient close to the bearing edge. This is due to the direct correlation between local pressure and local deformation due to the compliant liner. As in Figure 2, it is seen that the flexure tube of the flexure

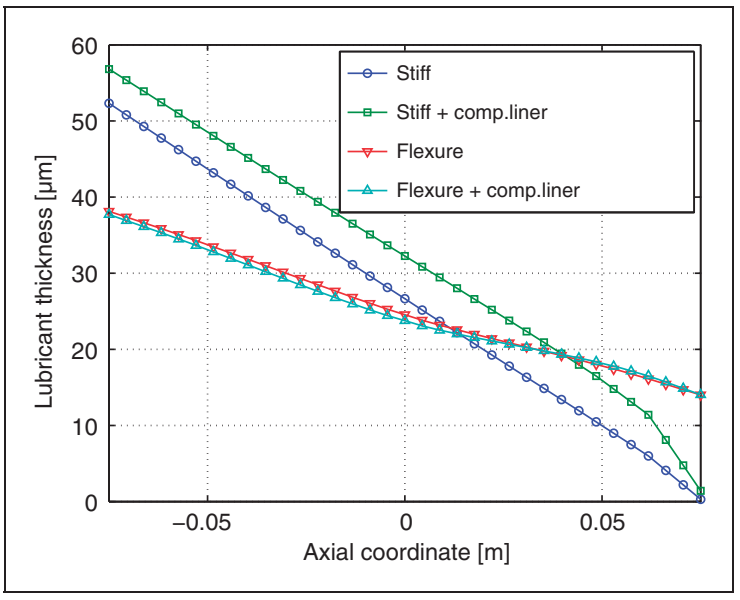

Figure II. Axial film thickness profiles for bearings with $225 \mathrm{kN}$ load and $0.44 \mathrm{mrad}$ misalignment at circumferential location with minimum film thickness.

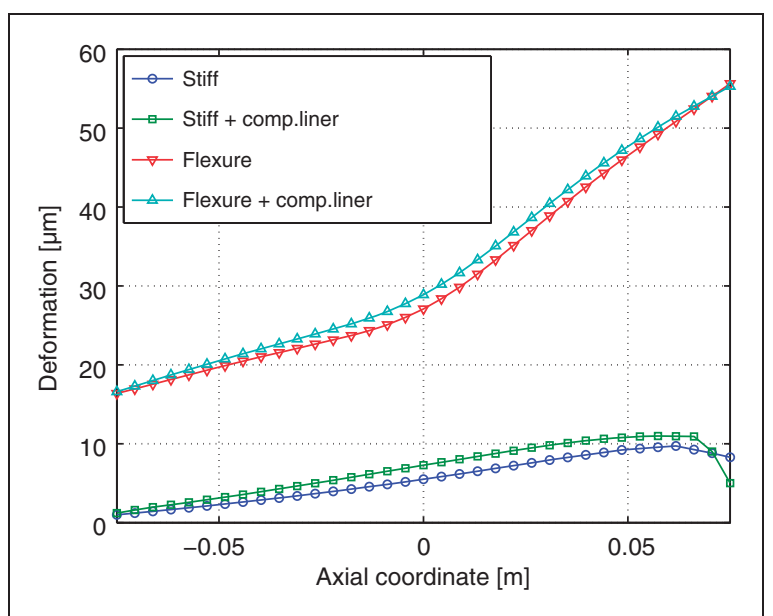

Figure 12. Axial liner deformation profiles for bearings with $225 \mathrm{kN}$ load and $0.44 \mathrm{mrad}$ misalignment at circumferential location with maximum deformation.

bearing bends at the centre where it is supported by the flexure web. Again, it seen that the compliant liner only influences the stiff bearing.

Figure 12 shows the bearing deformations. The deformation profiles explain why the flexure bearings exhibit lower bearing stiffness coefficients and therefore operate at higher eccentricity ratios, as shown in Figure 6. Again, the flexure tube bending is evident with the gradient change at the middle of the bearing. The results also show that even if the stiff bearing is modelled using a solid steel ring, it still has a significant deformation. Many bearing studies assume the bearing to be infinitely stiff. Figure 12 shows that this assumption does not hold true. 


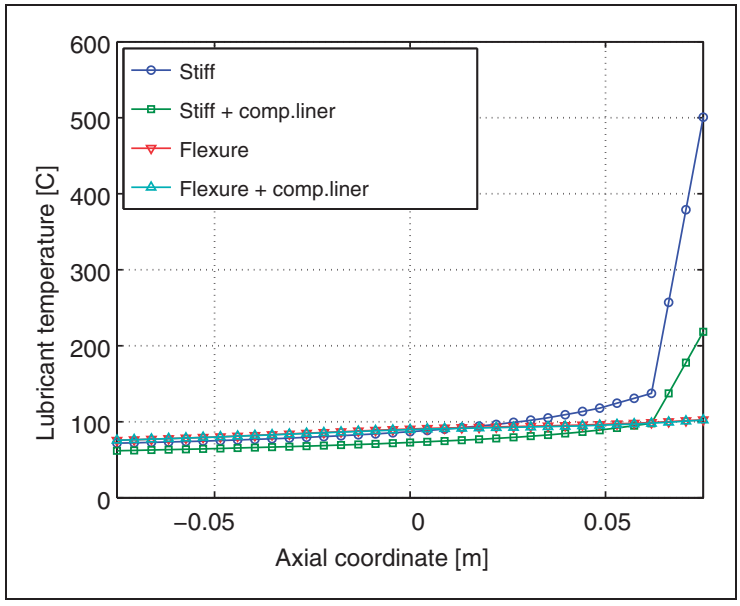

Figure 13. Axial temperature $T_{m}$ profiles for bearings with $225 \mathrm{kN}$ load and $0.44 \mathrm{mrad}$ misalignment at circumferential location with maximum temperature.

Figure 13 shows the axial temperature profiles. The stiff bearing leaps out with extremely high temperatures. This can be explained by the high-pressure gradients shown in Figure 10 in combination with the low film thickness of Figure 11. The stiff bearing with a compliant liner also shows a high-pressure peak at the bearing edge, it is, however, not as pronounced as for the stiff bearing. This can be explained by the increased film thickness that induces a higher lubricant flow in the hardest loaded area. The flexure bearings show only a moderate temperature increases over the axial length, as also shown in Figure 9.

\section{Conclusion}

Using a thermoelastohydrodynamic model, it is shown that the proposed flexure journal bearing design can effectively increase bearing performance when operating at high misalignments. This is achieved without reducing performance at low or no misalignment and also without adding extra components or systems that require fine machining. The proposed flexure design does, however, require extra space for the flexure web that may be difficult to combine with some bearing applications.

Based on the predicted minimum film thicknesses, the proposed flexure journal bearing can operate at three times the misalignment compared to the stiff bearings. This analysis was performed for a short journal bearing with a width- to diameter-ratio of 0.5 . The effects will be even more pronounced for bearings with higher ratios since these are more sensitive to misalignment.

The flexure tube must be as stiff as possible in order to give a wide pressure distribution in axial direction, whereas the flexure web must be compliant to allow for angular deformation when operating at misalignment. The lower thickness limit of the flexure web is determined from the structural strength as well as the radial stiffness of the flexure web.

The compliant liner shows a remarkable increase in the hydrodynamic performance when applied to the stiff bearing, also at low or no misalignment. The positive influence is, however, not seen on flexure bearings. The polymer liner does, however, still give the increased performance at boundary or mixed lubrication, giving better wear properties and lower friction. This comes with the side-effect of increased thermal insulation.

\section{Funding}

This work was supported by The Danish Agency for Science, Technology and Innovation (grant no. 08-041149).

\section{Acknowledgements}

The authors gratefully acknowledge the financial support provided by the Danish Agency for Science, Technology and Innovation.

\section{References}

1. Bouyer $\mathbf{J}$ and Fillon $\mathbf{M}$. Improvement of the thd performance of a misaligned plain journal bearing. J Tribol 2003; 125: $334-342$.

2. Bouyer $\mathbf{J}$ and Fillon $\mathbf{M}$. An experimental analysis of misalignment effects on hydrodynamic plain journal bearing performances. J Tribol 2002; 124: 313-319.

3. Bouyer J, Fillon M and Pierre I. Thermohydrodynamic behaviour of misaligned plain journal beaings: theoretical and experimental approaches. Tribol Trans 2003; 47: 594-604.

4. Fillon M. On the thermal effects in hydrodynmaic journal bearings. Int J Appl Mech Eng 2005; 3: 441-450.

5. Nikolakopoulos P, Papadopoulos C and Kaiktsis L. Elastohydrodynamic analysis and pareto optimization of intact, worn and misaligned journal bearings. Meccanica 2011; 46: 577-588.

6. Mihailidis A, Bakolas V, Panagiotidis K, et al. Influence of the bushing geometry on the thermohydrodynamic performance of a misaligned journal bearing. Proc IMechE Part J: J Engineering Tribology 2010; 224: 37-53.

7. Walton N and San Andrés L. Measurements of static loading versus eccentricity in a flexure-pivot tilting pad journal bearing. J Tribol 1997; 119: 297-304.

8. San Andrés L and de Santiago O. Imbalance response of a rotor supported on flexure pivot tilting pad journal bearings in series with integral squeeze film dampers. J Eng Gas Turbines Power 2003; 125: 1026-1032.

9. Thomsen K and Klit P. Geometrical design parameters for journal bearings with flexure pads. Proc IMechE Part J: J Engineering Tribology. Epub ahead of print, DOI: 10.1177/ 1350650111431525. 
10. Simmons J, Knox R and Moss W. The development of PTFE-faced hydrodynamic thrust bearing for hydrogenerator application in the united kingdom. Proc IMechE Part J: J Engineering Tribology 1998; 212: 345-352.

11. Thomsen K and Klit P. A study on compliant layers and its influence on dynamic response of a hydrodynamic journal bearing. Tribol Int 2011; 44: 1872-1877.

12. McIvor $\mathrm{J}$ and Fenner D. Finite element analysis of dynamically loaded flexible journal bearings. J Tribol 1989; 111: 597-604.

13. Huebner K, Dewhirst D, Smith D, et al. The finite element method for engineers. New York: John Wiley \& Sons, 2001.

14. Ansys. Version 12.1, http://www.ansys.com (2009, accessed 1 September 2011).

15. McIvor J. The analysis of dynamically loaded flexible journal bearings using higher-order finite elements. $\mathrm{PhD}$ dissertation. University of London, London, 1988.

16. Seeton J. Viscosity-temperature correlation for liquids. Tribol Lett 2006; 22: 67-78.

17. McCarthy D and Glavatskih S. Assessment of polymer composites for hydrodynamic journal-bearing applications. Lubr Sci 2009; 21(8): 331-341.

\section{Appendix}

\section{Notation}

$\begin{array}{ll}A & \text { element area }\left(\mathrm{m}^{2}\right) \\ A_{J} & \text { journal cross-sectional area }\left(\mathrm{m}^{2}\right) \\ \text { A } & \text { integration matrix }\left(\mathrm{m}^{2}\right) \\ b, c & \text { element coefficients }(\mathrm{m}) \\ c_{p} & \text { specific heat capacity of lubricant }(\mathrm{J} / \mathrm{kg} / \mathrm{K})\end{array}$

deformation vector $(\mathrm{m})$ modulus of elasticity $\left(\mathrm{N} / \mathrm{m}^{2}\right)$

functional $\left(\mathrm{m}^{3} / \mathrm{s}\right)$

force $(\mathrm{N})$

pad film thickness (m)

pad film thickness in the undeformed state $(\mathrm{m})$

fluidity matrix $\left(\mathrm{m}^{3} /(\mathrm{Pa} \mathrm{s})\right)$

journal thermal conductivity $(\mathrm{W} / \mathrm{m} / \mathrm{K})$

force stiffness matrix $(\mathrm{N} / \mathrm{m})$

journal width (m)

pressure compliance matrix $(\mathrm{m} / \mathrm{Pa})$

pressure $(\mathrm{Pa})$

power $(\mathrm{J} / \mathrm{s})$

lubricant flow $\left(\mathrm{m}^{3} / \mathrm{s}\right)$

radius $(\mathrm{m})$

residual $\left(\mathrm{m}^{3} / \mathrm{s}\right)$

journal temperature $(\mathrm{C})$

lubricant mean temperature $(\mathrm{C})$

fluidity vector $\left(\mathrm{m}^{3} / \mathrm{s}\right)$

$x, y, z \quad$ linear coordinates $(\mathrm{m})$

$\alpha_{J} \quad$ heat transfer coefficient between interface: journal/oil $\left(\mathrm{W} / \mathrm{m}^{2} / \mathrm{K}\right)$

$\theta \quad$ angular coordinate (rad)

$\mu \quad$ lubricant viscosity (Pa s)

$\mu_{m} \quad$ mean lubricant viscosity (Pa s)

$v \quad$ Poisson's ratio $(-)$

$\rho \quad$ lubricant density $\left(\mathrm{kg} / \mathrm{m}^{3}\right)$

$\omega \quad$ rotational speed $(\mathrm{rad} / \mathrm{s})$

$\Omega \quad$ area $\left(\mathrm{m}^{2}\right)$ 